\title{
Cultural Elements Analysis and Reconstruction of Elementary English Textbook -Focusing on Global Citizenship-
}

\author{
초등영어교과서 문화요소 분석 및 교육과정 재구성 \\ -세계 시민교육을 중심으로- \\ Hae Kyoung Lee ${ }^{1}$ \\ ${ }^{1}$ Professor, Department of English Education, Gongju National University of Education, Korea, \\ hklee@gjue.ac.kr
}

\begin{abstract}
As globalization spreads all over the world, English is being used as a major communication tool not only among those who speak their own language but also between people who are not English speakers. In addition to the ability to utilize the English language, understanding the relative culture can build relationship when people with diverse cultural backgrounds communicate. The revised curriculum that was announced by the Ministry of Education in 2015 suggested 'a human character who lives together with community spirit as a democratic citizen and practices consideration and kindness.' In order to achieve the educational objective, students should be taught to take the responsibility for their community's problem solving and regional development. School education should also make students get along as global citizens with community spirit and democratic civic awareness. The purpose of this study is to find out what to teach in civic education and how to teach civic education based on English textbooks. This study designed contents and methods of democratic civic education for elementary school students based on analysis of the 2015 revised curriculum and English text books. Furtheermore, it suggests the methods of civic education based on English textbooks. This study is intended to provide direction to democratic civic education in elementary English education and a guide for a reconstruction of English curriculum.
\end{abstract}

Keywords: 2015 Revised Curriculum, Global Civic Education, Cultual Elements Analysis, Elementary English Textbook, Reconstruction

요약: 세계화의 확대로 인해 영어는 세계 전 지역의 사람들 간에 의사소통의 도구로 이미 활용되고 있다는 것은 주지의 사실이다. 다양한 문화적 배경을 가진 사람들이 의사소통을 하고자 할 때, 언어로서의 영어 활용 능력은 물론이고 상대 문화에 대한 이해와 존중의 자세를 지녀야 원활한 소통 및 관계를 만들 수 있다. 이에 본 연구에서는 2015 개정 교육과정 중 초등학교 영어 교과서를 대상으로 각 교과서에서 문화요소를 어떻게 다루고 있는지 살펴보고, 학생들이 실제 지구촌에서 일어나고 있는 여러 문제들을 해결해 보며 세계시민의식을 함양할 수 있도록 교육과정을 재구성하고자 한다. 초등영어 문화 분석은 2015 개정 교육과정을 기본으로 하여 5명의 현직 교사인 대학원 학생들이 재직하고 있는 초등학교의 A교과서 중심으로 3-6학년 모두를 대상으로 선정하여 영어 교과서에 있는

Received: September 9, 2021; $1^{\text {st }}$ Review Result: October 23, 2021; $2^{\text {nd }}$ Review Result: December 13, 2021 Accepted: January 29, 2022 
문화 교육 내용을 중심으로 세계시민교육 구성 요소와 연관성을 찾을 수 있는 부분을 발췌하여 이를 바탕으로 4차시 프로젝트 수업을 하였으며, 3·4학년군은 세계화 알기, 문화의 다양성과 전지구적 가치의 동질성 알기로 구성하였고, 5.6학년군은 세계의 다양한 쟁점과 우리와의 연관성 알기, 행동적 가치 실현, 실생활에서 세계 시민성 내면화로 구성하였고 그 중 $5 \cdot 6$ 학년군을 대상으로 의사소통 요소와 문화요소를 중심으로 지도안을 재구성하였다.

핵심어: 2015 교육과정, 세계시민교육, 문화요소 분석, 초등영어 교과서, 재구성

\section{1. 서론}

미래사회를 위한 교육을 설계함에 있어서 한 국가의 국민이자 세계의 시민으로서 학생들에게 세계에서 일어나는 다양한 문제들에 대해 함께 생각하고 고민하며 행동할 수 있도록 교육해야 할 필요가 있다. 이러한 세계 시민으로서의 역량을 함양하기 위해 초등영어 교과를 대상으로 교재의 내용을 분석해 보고 재구성을 하고자 한다. 본 연구에서는 2015 개정 교육과정 중 초등학교 영어 교과서를 대상으로 각 교과서에서 문화요소를 어떻게 다루고 있는지 살펴보고, 학생들이 실제 지구촌에서 일어나고 있는 여러 문제들을 해결해 보며 세계시민의식을 함양할 수 있도록 교육과정을 재구성하고자 한다.

이를 위해 교과서의 문화 교육 내용을 분석한 후 각 부분들이 세계시민교육과 잘 연계되어 있는지 확인하고, 3·4학년군 교과서에서 이루어지고 있는 세계 시민교육과 5.6학년군 교과서에서 이루어지고 있는 세계시민교육이 서로 유기적으로 연결되고 발전되고 있는지를 살펴보고 현재 세계에서 일어나고 있는 다양한 문제들과 연관하여 재구성할 수 있는 부분이 있는지 확인한다. 또한, 재구성한 영어과 교과 과정을 통해 학생들이 영어 의사소통 능력과 세계시민교육 목표를 실제로 달성할 수 있을지 여부를 검토한다.

본 연구를 위해 초등영어교재의 문화요소 부분을 분석한 후 다음과 같이 두 단계에 걸쳐 수업을 재구성한다. 첫째, 다음 내용과 관련하여 교과서를 분석한다. 본 연구자가 가르치고 있는 대학원 재학생 중인 현직 초등 교사들이 가장 많이 사용하고 있는 $\mathrm{A}$ 교과서 (3-6학년) 문화 부분 내에서 확인할 수 있는 세계 시민교육과 그 내용 요소를 확인하고 학년군별 세계 시민교육 관련 요소들이 학년이 올라가며 심화·발전 제시되고 있는지를 확인한다. 둘째, 교과서를 연구한 문화 내용 중 현재 진행되고 있는 세계의 여러 문제들과 연관 지을 수 있는 부분이 있는지 확인 후 영어교육 과정 재구성에 알맞은 내용을 선정하여 재구성을 하고 교수·학습 과정안을 작성한다.

\section{2. 이론적 배경}

\section{1 세계 시민교육의 정의}

$\mathrm{UNESCO}(2014)$ 는 다양성에 대한 존중을 바탕으로 인류에 소속감을 느끼고 지역과 세계를 연결시켜 이해하며, 자신과 타인, 환경을 폭넓게 이해하는 것을 세계 시민성이라고 보았으며, Banks(2008)는 지구적 차원에서 전 인류가 하나의 지구 공동체 속 
구성원으로서 가지게 되는 권리 및 의무를 세계시민성이라고 정의하였다[1][2]. $\operatorname{OXFAM(2015)ㅇㅡㄴ~ㅅㅔㄱㅖ~ㅅㅣㅁㅣㄴㅅㅓㅇㅇㅡㄹ~ㅅㅔㄱㅖ~ㅅㅣㅁㅣㄴㅇㅢ~ㄱㅐㄴㅕㅁㄱㅘ~ㅇㅕㄴㄱㅕㄹㅎㅏㅇㅕㅆㄴㅡㄴㄷㅔ,~ㄴㅓㄼㅇㅡㄴ~ㅅㅔㄱㅖㅇㅔ~ㄷㅐㅎㅏㄴ~}$ 인정을 바탕으로 자신의 역할을 인식하고, 다양성 존중과 사회정의 실현을 위해 노력하는 태도를 갖추며, 세계를 평등하게 만들고자 행동하는 사람을 세계 시민으로 보았다. 또한 세계시민성의 구성 요소를 평화와 갈등, 인권과 같은 지식적 측면, 공감능력, 의사소통 능력 등의 기능적 측면, 다양성을 가치 있게 여기고, 환경에 대한 관심을 갖는 등의 태도적 측면으로 나누었다[3].

\section{2 초등영어 교육과 세계 시민교육}

2015 개정 교육과정 총론에서는 추구하는 인간상으로 문화적 소양과 다원적 가치에 대한 이해를 바탕으로 인류 문화를 향유하고 발전시키는 교양 있는 사람과 공동체 의식을 가지고 세계와 소통하는 민주시민으로서 배려와 나눔을 실천하는 더불어 사는 사람을 제시하고 있다[4]. 이는 2015 개정 교육과정을 통해 학생들이 세계시민이 갖추어야 할 다문화의 수용과 문화 발전의 책무성을 나타내고 있으며, 범지구적 공동체의 일원으로서 지켜야 할 기본적인 시민 의식을 갖추어야 함을 명시하고 있다. 2015 개정 교육과정은 위와 같이 추구하는 인간상과 핵심 역량에서 많은 부분 세계 시민교육과 관련된 내용을 명시적으로 제시하면서 이를 중요한 내용으로 강조하고 있다. 이와 같이 초등영어교육은 기본적으로 세계 시민 교육의 내용 뿐 만 아니라 세계 시민의식의 함양을 위한 가장 기초적인 능력으로 타 문화간 의사소통 능력을 강조하고 있다.

\section{3 선행연구}

초등영어교육과 세계 시민교육을 연계하여 최근 들어 여러 연구가 진행되어오고 있다. 이경진(2017)의 논문에서는 세계시민교육과 관련한 영어과의 내용과 사회과를 통합한 수업을 구성하였고, 유호성(2017)은 초등학생의 세계 시민으로서의 글로벌 마인드 함양과 글로벌 리더로서의 자질 함양을 위한 초등영어 세계시민의식 함양 교수학습 모형을 구상하고 실제 수업에 적용하고자 연구하였다[5][6]. 이 외에도 초등영어교육과 세계 시민교육을 연계하여 김지은(2019)은 세계시민의식 함양을 위한 프로젝트 기반 초등영어 수업의 구안과 적용에 대해 연구하였고, 유효성과 강정진(2017)은 KDB모형을 기반으로 한 주제중심 초등영어 교수학습 방안에 관하여 세계시민의식과 표현능력을 중심으로 연구하였다. 이 밖에도 송미경(2018)의 논문에서는 문화간 향상을 위한 세계시민 통합 초등 영어수업에 대한 연구를 하였다[7][8][9].

\section{2015 개정 교육과정 내 세계 시민교육 관련 문화 내용 분석}

\section{1 초등영어 수업 재구성 상의 교육과정 흐름 5단계}

아래 5 단계 흐름에 맞추어 영어과목을 배우는 전 학년이 세계 시민교육을 받을 수 있도록 구성하되, 학습 능력 및 이해도의 차이가 있음을 예상하여 구성한다. 이에 따라 $3 \cdot 4$ 학년군(1-3단계)과 5·6학년군(4-5단계)을 분리하여 수업안을 재구성한다. 
[표 1] 수업재구성 상 교육과정의 흐름

[Table 1] The Flow of the Curriculum for Reorganizing Classes

\begin{tabular}{|c|c|c|c|c|c|c|c|c|}
\hline $\begin{array}{l}\text { 1. 세계화로 } \\
\text { 인해 달라진 } \\
\text { 우리의 삶 인식 }\end{array}$ & $\rightarrow$ & $\begin{array}{l}\text { 2. 문화의 } \\
\text { 다양성 } \\
\text { 체감 } \\
\text { (다름을 앎) }\end{array}$ & $\rightarrow$ & $\begin{array}{l}\text { 3. 문화 초월적 } \\
\text { 세계 정서 인식 } \\
\text { (같음을 앎) }\end{array}$ & $\rightarrow$ & $\begin{array}{c}\text { 4. 전지구적 } \\
\text { 문제에 대한 } \\
\text { 공동의 문제의식 } \\
\text { 제고 }\end{array}$ & $\rightarrow$ & $\begin{array}{c}\text { 5. 세계에 } \\
\text { 기여하고자 하는 } \\
\text { 태도 함양 }\end{array}$ \\
\hline
\end{tabular}

\section{2 초등영어교과서 문화분석}

가. 3학년 교과서 본문 및 문화요소 소개 부분 분석

나. 4학년 교과서 본문 및 문화요소 소개 부분 분석

다. 5학년 교과서 본문 및 문화요소 소개 부분 분석

라. 6학년 교과서 본문 및 문화요소 소개 부분 분석

마. 교과서 각 학년별 문화 요소 연계

[표 2] 학년별 문화요소 연계

[Table 2] Associated with each Grade of Culture

\begin{tabular}{|c|c|c|c|}
\hline 단원 & 영어 의사소통 지도 요소 & 문화 요소 & $\begin{array}{l}\text { 학년 연계 } \\
\text { (학년-단원) }\end{array}$ \\
\hline How was your trip? & $\begin{array}{l}\text { 과거 경험을 묻고 답하는 말하기 } \\
\text { How was your ?/It was } \\
\text { 과거 사실을 묻고 답하는 말하기 } \\
\text { Did you ?/Yes, I did/No, I didn't }\end{array}$ & $\begin{array}{c}\text { 자연 경관이 유명한 } \\
\text { 곳 }\end{array}$ & $\begin{array}{c}3-4,3-7 \\
4-8,5-4 \\
6-7\end{array}$ \\
\hline $\begin{array}{l}\text { I exercise four times } \\
\text { a week }\end{array}$ & $\begin{array}{c}\text { 빈도수를 묻고 답하는 말하기 } \\
\text { How often do you ? } \\
\text { /I / exercise/times/week/brush } \\
\text { 격려하는 표현 말하기 } \\
\text { You can do it }\end{array}$ & 건강한 생활습관 & $6-12$ \\
\hline $\begin{array}{l}\text { What season do you } \\
\text { like? }\end{array}$ & $\begin{array}{c}\text { 좋아하는 계절 묻고 답하기 } \\
\text { What season do you like? } \\
\text { /I like /spring/summer/fall/winter/because } \\
\text { 헤어질 때 하는 인사말하기 } \\
\text { See you/Take care }\end{array}$ & $\begin{array}{l}\text { 명화 속에 나타난 } \\
\text { 계절 }\end{array}$ & $3-9,5-11$ \\
\hline $\begin{array}{l}\text { What do you want to } \\
\text { be? }\end{array}$ & $\begin{array}{c}\text { 장래희망을 묻고 답하는 말하기 } \\
\text { What do you want to be?/I want to be a /pilot/driver }\end{array}$ & 이색적인 직업 & $5-6,6-3$ \\
\hline
\end{tabular}




\begin{tabular}{|c|c|c|c|}
\hline & $\begin{array}{l}\text { 낙담을 위로하는 표현 말하기 } \\
\text { Come on/You can do it }\end{array}$ & & \\
\hline \multirow{2}{*}{ I have a headache } & $\begin{array}{c}\text { 아픈 곳을 묻고 답하는 말하기 } \\
\text { What's wrong?/I have a / } \\
\text { headache/fever/stomachache }\end{array}$ & \multirow{2}{*}{ 감기치료에 좋은 음식 } & \multirow{2}{*}{$\begin{array}{c}3-4,4-8 \\
6-2\end{array}$} \\
\hline & $\begin{array}{c}\text { 유감이나 동정을 나타내는 표현 말하기 } \\
\text { That's too bad }\end{array}$ & & \\
\hline \multirow{2}{*}{$\begin{array}{l}\text { When is the school } \\
\text { festival? }\end{array}$} & $\begin{array}{c}\text { 날짜를 묻고 답하는 표현 말하기 } \\
\text { When is the ?/It's / th }\end{array}$ & \multirow{2}{*}{ 세계의 기념일 } & \multirow{2}{*}{$\begin{array}{c}3-11,4-13 \\
5-5\end{array}$} \\
\hline & $\begin{array}{c}\text { 반복 요청하는 표현 말하기 } \\
\text { I'm sorry? }\end{array}$ & & \\
\hline \multirow{2}{*}{ Congratulations } & $\begin{array}{c}\text { 계획을 묻고 답하는 표현 말하기 } \\
\text { What are you going to do after } \sim ? \\
\text { /I'm going to }\end{array}$ & \multirow{2}{*}{$\begin{array}{c}\text { 각 나라의 졸업하는 } \\
\text { 시기 }\end{array}$} & \multirow{2}{*}{$\begin{array}{c}3-13,4-6 \\
5-1\end{array}$} \\
\hline & $\begin{array}{l}\text { 축하하는 표현 말하기 } \\
\text { Congratulations }\end{array}$ & & \\
\hline
\end{tabular}

3-6학년 각 단원의 문화요소와 연계된 단원들을 표시해 보니 대부분의 문화 요소들이 유기적으로 연결되어 있는 것을 확인할 수 있었다. 3 학년과 4 학년의 경우 같은 학년군 내에서 비슷한 문화 요소를 다루는 경우가 많음을 확인할 수 있고, 5 학년과 6학년의 경우 같은 학년군 뿐만 아니라 전 학년에 걸쳐 다양한 문화요소를 다루는 것을 확인할 수 있다. 또한 6 학년의 경우, 단순한 문화요소의 나열이 아니라 친환경 도시 등 환경문제에도 관심을 갖고 다룰 수 있도록 세계의 이슈에 대한 다양한 문화 파트를 구성하였다[10][11][12][13].

\section{4. 세계 시민교육 영어수업 지도안 재구성}

\subsection{3·4학년군 세계 시민교육 기반 영어수업 재구성 차시 목표 예시}

[표 3] 3·4학년군 세계 시민교육 기반 영어수업 재구성 차시 목표

[Table 3] The Goal of Reconstruction English Classes based on Global Civic Education (3-4 grade Group)

1차시 수업 목표(말하기, 쓰기)

(지식·이해) 세계화로 인해 달라진 우리 삶의 모습을 알 수 있다.

(옛날 한국 전통 음식, 현재 한국 전통 음식 비교)

(기능) 비판적 사고력을 통해 과거와 현재를 비교할 수 있다.

음식의 호불호를 나타내는 표현(3-4), 음식을 소개하는 표현(3-4), 음식을 권하는

표현(4-8) 등을 적절히 사용해 발표할 수 있다.

(가치) 사회의 변화를 받아들이고 이에 대응할 수 있는 태도를 지닐 수 있다. 
2-3차시 수업 목표(말하기, 듣기, 읽기)

(지식·이해) 서로 다른 문화 사이에 차이가 있음을 이해하고, 문화 간 다양성이 존재함을

알 수 있다. (다른 나라의 전통 음식 소개)

(기능) 음식을 소개하는 표현(3-4) 등을 적절히 사용하여 동료들과 자신이 가진 정보를

교환하며 의사소통할 수 있다.

(가치) 나와 다른 문화와 가치를 존중할 수 있다.

4차시 수업 목표(말하기, 듣기)

(지식·이해) 서로 다른 문화 간에도 전지구적인 세계시민의식이 있음을 알 수 있다.

(기능) 다양한 사례 속에서 공통점을 이끌어 낼 수 있다. (서로 다른 나라 사람들이 가족과

함께 음식을 나누며 즐거워하는 모습, 세계 음식 박람회 등 소개)

(가치) 전지구적인 가치를 수호하려는 태도를 지닐 수 있다.

\subsection{6학년군 세계 시민교육 기반 영어수업 재구성 차시 목표 예시}

[표 4] 5·6학년군 세계 시민교육 기반 영어수업 재구성 차시 목표

[Table 4] The Goal of Reconstruction English Classes based on Global Civic Education (5-6 Grade Group)

1차시 수업 목표(읽기)

(지식·이해) 나라가 달라도 공통적인 세계시민의식이 있음을 알 수 있다.

(기능) 다양한 사례 속에서 공통점을 이끌어 낼 수 있다. (우리나라 관광지의 환경이 오염

되는 모습, 다른 나라 관광지의 환경이 오염되는 모습)

유명한 장소(5-13), 관광지(6-5), 자연 경관이 유명한 곳(6-8)과 관련하여 영어로 된

읽기 자료를 읽고 그 내용에 대해 토의할 수 있다.

(가치) 전지구적인 가치를 수호하려는 태도를 지닐 수 있다.

2-3차시 수업 목표(말하기, 듣기)

(지식·이해) 전 지구적으로 해결해야 할 문제와 이를 위한 노력을 알 수 있다.

(기능) 문제를 해결하기 위해 합리적인 방안을 제안할 수 있다.

상태를 비교하는 표현(6-6), 도움을 요청하는 표현(5-2), 제안하는 표현(6-4)를

영어로 표현할 수 있다.

(가치) 더 나은 세계를 만들기 위해 관심을 기울이는 태도를 지닐 수 있다.

4차시 수업 목표(쓰기) 
(지식·이해) 지구와 세계를 위하는 일이 무엇인지 알 수 있다.

(기능) 방학 중 환경을 보호하기 위해 할 일(6-7)을 계획할 수 있다.

자신과 타인이 한 잘한 행동에 대해 칭찬(5-4)하는 단어 및 문장을 쓸 수 있다.

(가치) 세계시민으로 성장해 지구에 기여하고자 하는 태도를 지닐 수 있다.

\section{3 교수·학습과정안의 예(5·6학년군)}

[표 5] 재구성 1 차시

[Table 5] Reconstruction 1

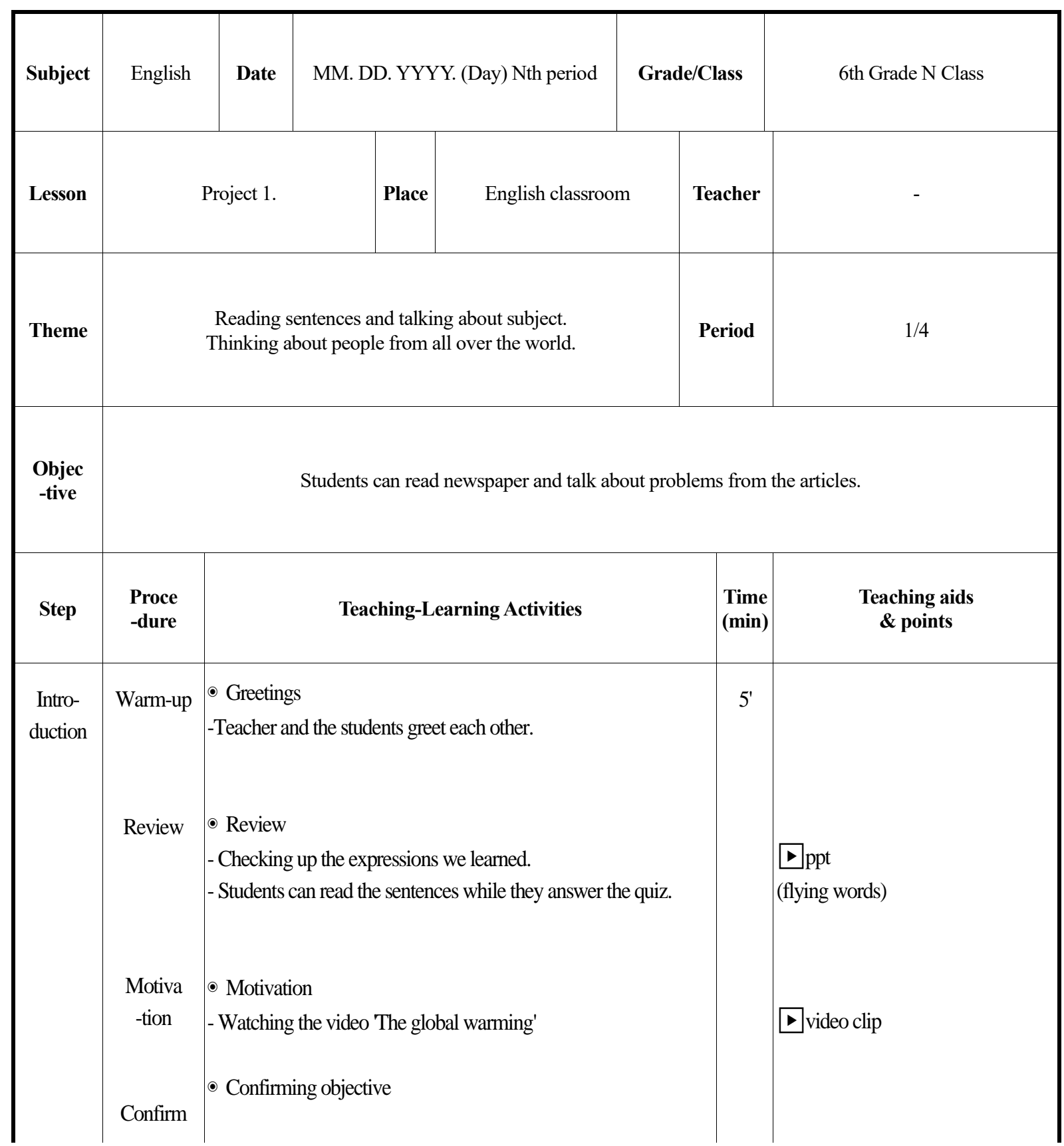




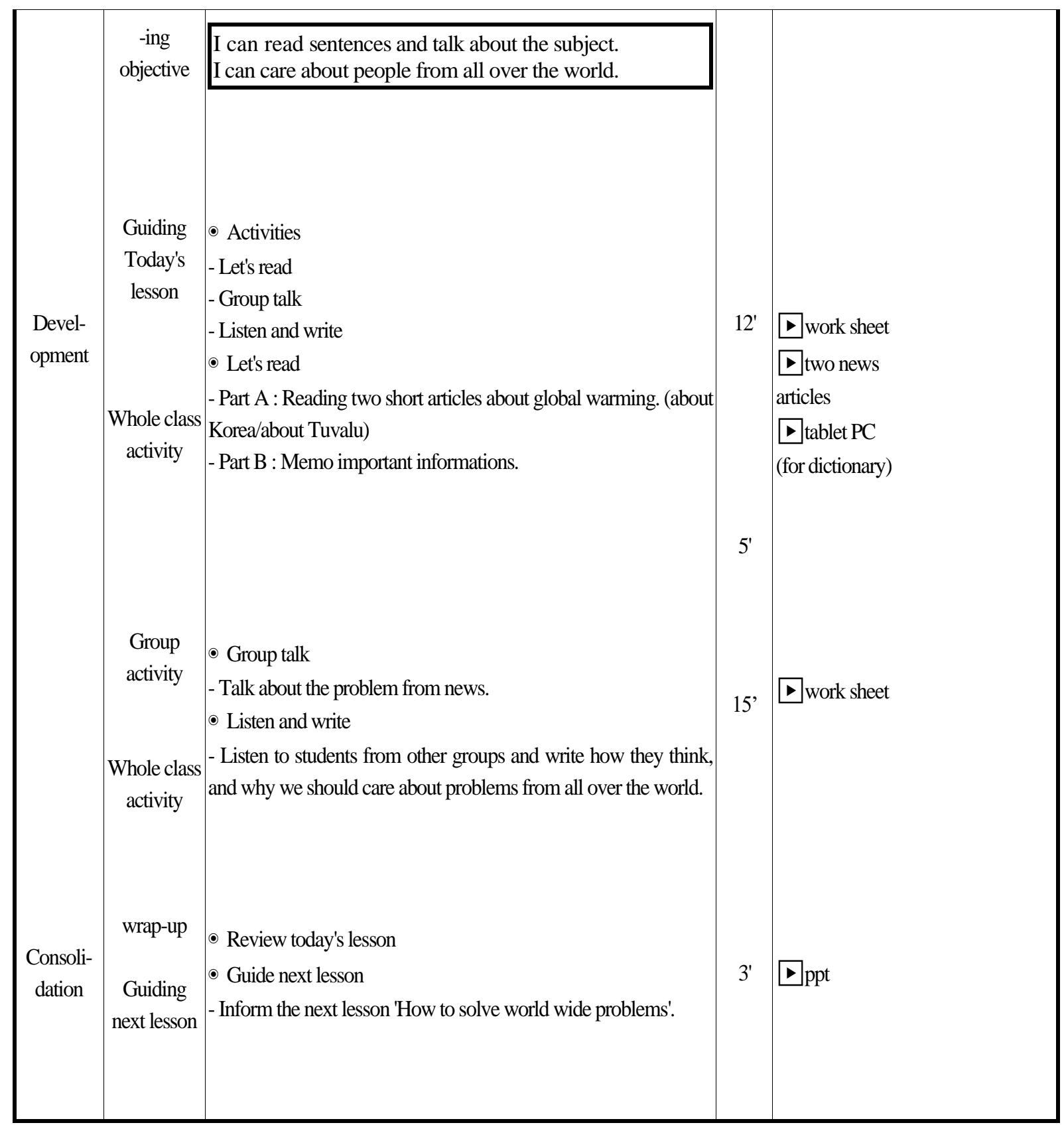

\section{5. 결론}

급속도로 변해가는 현대사회의 흐름을 반영하여, 교육에서도 지속가능한 개발 계획 및 세계 시민교육을 강조하고 있는 점을 고려할 때 초등영어 교육과정 중 세계 시민교육 관련 요소를 중심으로 의사소통 요소 및 문화 요소 내용들을 분석하여 재구성해야 할 필요성이 있다.

초등영어 교과서 문화 분석은 2015 개정 교육과정을 기본으로 하여 5 명의 현직 교사인 대학원 학생들이 재직하고 있는 초등학교에서 가장 많이 채택하여 사용 중인 A교과서 중심으로 하였다. 대상 학년은 영어 교과를 학습하는 3-6학년 모두를 대상으로 선정하였고 영어교과가 제시하는 목표, 주요 표현이나 문화 교육 내용, 교수 방법 등에서 
세계시민교육 구성 요소와 연관성을 찾을 수 있는 부분을 발췌하여 이를 바탕으로 4차시 프로젝트 수업을 구상하였다. 3·4학년군은 세계화 알기, 문화의 다양성과 전지구적 가치의 동질성 알기로 구성하였고, 5.6학년군은 세계의 다양한 쟁점과 우리와의 연관성 알기, 행동적 가치 실현, 실생활에서 세계 시민성 내면화로 구성하였다. 그 중 5.6학년군을 대상으로 의사소통 요소와 문화요소를 중심으로 지도안을 재구성하였다.

본 연구의 제한점으로 첫째, 교육과정을 재구성할 때 염두에 두고 작성한 대상이 대규모 학교의 학생들이라는 점이다. 이는 학교 현장에서의 보편적인 교육과정으로 적용하기에는 어렵다고 볼 수 있다. 둘째, 구성한 지도안의 검증 미비이다. 재구성한 지도안을 가지고 실제 대상 학생을 선정하여 실험 및 사전사후 검사 등을 진행하지 않아 재구성한 교육과정이 실제로 유의미한 효과를 가져올 구성 내용이나 지도 방법을 사용하였을 경우에 대한 차후 연구가 필요하다.

그럼에도 불구하고 세계 시민교육을 주제로 한 본 영어과 교육과정의 분석 및 재구성이 가지는 의의가 있다. 첫째, 모든 교육과정은 각 교사가 속해있는 학교에 정확히 들어맞기는 어렵다. 따라서 큰 규모의 학교에서는 재구성했던 지도안을 바탕으로 조금 더 융통성 있게 지도할 수 있음에 그 의의가 있다. 둘째, 초등학교 영어 수업 현장에서 세계시민교육의 시행을 위해 조금 더 관심을 가지며 영어과 교육과정을 연구하고 이를 바탕으로 학생들이 세계시민으로 발전해 나가는 기초자료가 될 수 있기를 기대한다.

\section{References}

[1] UNESCO education strategy 2014-2021, UNESCO pp.1-63, (2014), https://unesdoc.unesco.org/ark:/48223/ pf0000231288

[2] J. A. Banks, An Introduction to Multicultual Education, 4th editon, Pearson, pp.289-298, (2007)

[3] Education for Global Citizenship: A Guide for Schools, Oxfam, pp.8-32, (2015)

[4] Vol.2015-74 Elementary English Curriculum, Ministry of Education, pp.1-2, (2015)

[5] K. J. Lee, A study on constructing integrated curriculum of English education and social studies education based on global citizenship education, Graduate School of Seoul University of Education, Master's thesis, pp.1-87, (2017)

[6] H. S. Ryu, A Study on Teaching and Learning Method of Theme-centered Intergrated Elementary English teaching for Cultivating Global Citizenship, Graduate School of Gyeongin University of Education, Master's thesis, pp.1-85, (2017)

[7] J. E. Kim, A study on teaching and learing method of project-based elementary English teaching for cultivating global citizenship, Graduate School of Gyeongin University of Education, Master's thesis, pp.1-82, (2019)

[8] H. S. Ryu, J. J. Kang, The study on theme-based integrated elementary English instruction based on KDB model, Primary English Education, (2017), Vol.23, No.4, pp. 123-146, DOI: http://dx.doi.org/10.25231/pee.2017.23.4.123

[9] M. K. Song, A study of the global citizenship education integrated English class for developing intercultural communicative competence, Graduate School of Seoul University of Education, Master's thesis, pp.1-61, (2018)

[10] H. R. Kim, J. S. Kyoung, Y. H. Jeong, H. J. Im, J. H. Lee, T. Y. Kim, Y. U. Kang, Elementary School English 3 Textbook and Teacher's guide book, YBM, pp.8-121, pp.56-309, (2018)

[11] H. R. Kim, J. S. Kyoung, Y. H. Jeong, H. J. Im, J. H. Lee, T. Y. Kim, Y. U. Kang, Elementary School English 4 Textbook and Teacher's guide book, YBM, pp.8-121, pp.56-309, (2018)

[12] H. R. Kim, J. S. Kyoung, Y. H. Jeong, H. J. Im, J. H. Lee, T. Y. Kim, Y. U. Kang, Elementary School English 5 Textbook and Teacher's guide book, YBM, pp.8-183, pp.60-439, (2018). 
Cultural Elements Analysis and Reconstruction of Elementary English Textbook -Focusing on Global Citizenship-

[13] H. R. Kim, J. S. Kyoung, Y. H. Jeong, H. J. Im, J. H. Lee, T. Y. Kim, Y. U. Kang, Elementary School English 6 Textbook and Teacher's guide book, YBM, pp.8-183, pp.60-439, (2018). 